\title{
Airline Service Quality and Economic Factors: An ARDL Approach on US Airlines
}

\begin{abstract}
This study examines the impact of interest rates, fuel prices, and market concentration on airline service performance. Rather than foc using on an airline-level analysis, we employ aggregated data from the US Department of Transportation (DOT) and the Airline Consumer Report (ACR) to explore four airline service performanc e metrics, namely: on-time performance, cancelled flights, mishandled baggage, and passenger's complaints. We gauge the long run effect of the variables of interest using an Autoregressive Distributed Lag bound approach. The findings reveal long-term linkages between airline service levels and the variation in interest rates and market concentration providing new evidence on the trade-off relation between financial pressures and service quality and has practical implications for both regulators and airline managers. Our results are robust to business cycle effects including the great recession.
\end{abstract}

Keywords: Airline Service Levels, ARDL Bound Test, Market Concentration 


\section{Introduction}

Variations in economic conditions measured by the cost of borrowing and the pricing of important industrial commodities such as oil, as well as, in the market structure reflected by the consolidation of major players, have a direct or indirect effect on the financial performance of individual airlines, but also on the whole sector. After-effects of shocks on such critical cost factors may also affect the level of service quality offered to passengers leading to a degradation of service quality levels. The literature proposes several models (Dionne, Gagné, Gagnon, \& Vanasse, 1997; Golbe, 1988; Maksimovic \& Titman, 1991) which predict this relationship and postulate that a plausible strategy for firms to achieve their short-term goals is to trade-off the quality of their products. Moreover, the theory suggests that this association should be more apparent to financially weaker firms.

Another channel through which those factors may affect the airline service quality, is through their interlinked service supply chains (e.g., through code sharing, pooling of resources). Considering the efficiencies of pooling service supply chains in this sector, most airlines operate on a flight-only basis, outsourcing many critical activities to other organizations as service contracts. In that case, for a passenger flying from airport $A$ to $B$ with a particular airline, a web of different companies is going to be responsible for the check-in procedure, the ground handling services, the maintenance of the aircraft, and the crew. However, if one of these sub-contracted service providers experiences a service failure (e.g., a baggage loss), the airline is still liable towards the customer, and its performance record is affected. Taking into account the vast web of interconnected industries that are responsible for delivering the final service to the passenger, firm-specific characteristics may provide myopic information to operation managers (Choi, Wallace, \& Wang, 2016). As such, it is natural to consider information coming from common risk factors for all firms.

In the context of civil aviation, empirical studies ignore systematic cost factors that may affect the whole sector. Being able to anticipate that kind of risk is a matter of particular economic significance to an airline's operational planner, given that such information can in many cases lead to firm-specific actions like hedging and debt restructuring (e.g., postponing new aircraft orders, cancelling new routes, extending option contracts for fuel supply, dropping one service provider for another). Considering all 
the above, our study evaluates the effects of systemic cost components on the operational performance of the US aviation industry by aggregating performance metrics, publicly available from the US Department of Transportation.

More specifically, our study aims to assess the impact of market conditions and economic factors on four widely used aspects of operation performance: (i) flight delays, (ii) flight cancellations, (iii) volume of mishandled baggage and (iv) number of passengers' complaints. Our study contributes to the existing literature by providing an understanding of how sector-wide airline service levels are affected by macro (or systematic) economic factors in three ways. First, our macroscopic analysis in the airline sector provides opportunities for a more extensive analysis than what can be performed at a firm-level This means that summarizing company-specific data at industry-level would allow the universe of airlines to participate in our analysis without any loss of information, particularly for small airlines that often entail missing values in firm-specific controls. Second, by considering that the effects of macroeconomic factors in airline service performance may vary across the individual components of service quality outlined above, we utilize the Autoregressive Distributed Lag Model (ARDL) introduced by Pesaran and Shin (1999). This allows model identification flexibility in the distribution of lag lengths by permitting a mixture of integration order for the explanatory variables for each aspect of operational performance. Third, we examine economic effects controlling for significant structural breaks in our test period including the 2008-2009 recession as well as upward trends in flight volume.

Our results reveal that base interest rate pressures and to some extent market concentration can explain variations in facets of operational quality across the aviation industry. We also find significant effects when we account for structural breaks and trends across the period of study, such as mergers and acquisitions during the great recession and general upward trends on airline passenger volume. Bearing in mind the impact of operational performance on the service offering of airlines to customers, operation managers should consider the long-run effects of these variables, especially in an environment where service contracts are highly interlinked. Our results are also of importanc e to policymakers such as those tasked with handling passenger complaints and civil aviation authorities that regulate minimum service provision levels from airlines to passengers. Considering that our study is focused on the US aviation 
market, a market highly criticized by passengers and regulators for its service performance in various levels, this study provides a timely and critical topic for debate for researchers and practitioners.

To this end, this paper is structured as follows. Section 2 provides a review of the related literature where the literature gap is explored and identified. Section 3 describes the data and variables used in the analysis presented in Section 4. We provide a discussion about theoretical and managerial implication of the findings in Section 5 and we conclude the limitation as well as the possible avenues for future research on Section 6.

\section{Related Literature}

\subsection{Airline Service Quality}

Hitherto, literature has studied airline service quality from different perspectives. The vast majority of studies propose metrics to capture accurately service quality (Chou, Liu, Huang, Yih, \& Han, 2011; Higgins, Lawphongpanich, Mahoney, \& Yin, 2008; Korfiatis, Stamolampros, Kourouthanassis, \& Sagiadinos, 2019; Liou \& Tzeng, 2007) and focuses on the service quality factors that passengers value more (Babbar \& Koufteros, 2008; Gilbert \& Wong, 2003; Pakdil \& Aydın, 2007) usually through SERVQUAL or its modifications. Other studies discuss differences of service quality among carriers or differences in customer expectations from different service providers such as low cost versus legacy carriers (David Mc A, 2013; Wittman, 2014). Finally, a signific ant part of this literature examines the effect of airline service quality on passenger intentions, and as a consequence, on firm profitability (Hussain, Al Nasser, \& Hussain, 2015; Park, Robertson, \& Wu, 2006; Saha \& Theingi, 2009). However, the literature that explores the antecedents of the provided service quality is scarce with notable exceptions the stream of research that investigates a distinct aspect of airline quality, namely the airline safety.

To this end, several studies try to evaluate whether airline accident rates can be explained by the financial pressures that are experienced by airline carriers. Rose (1990) using data from 35 large US air carriers for the period 1957-1986 deduces that lower profitability is correlated with higher accident and incident rates, especially for smaller carriers. Noronha and Singal (2004) find similar results while they 
employ bonds rating of airline carriers as a measure of financial health. Raghavan and Rhoades (2005) confirm these results further by identifying an inverse relationship between financial performance and accident rates for smaller air carriers. More specifically the authors report an increase of accident rates (normalized over departures) since 1978 and a reversal of the previously declining trends raising concerns that safety improvements are not in the same pace with the growth of the aviation market. Nonetheless, even in those studies, the focus is on firm-specific variables while the effect of general economic conditions that may influence the whole sector is ignored. Insofar, the focus on the study of economic drivers in extant air transport literature is on the relationship of air transport demand (or air transport infrastructures) on economic growth and its directionality (Hakim \& Merkert, 2016; Marazzo, Scherre, \& Fernandes, 2010; Saidi, Shahbaz, \& Akhtar, 2018).

\subsection{Airline Service Levels and Financial Performance}

The question of whether and how a firm's financial position has an effect on the product (or service) quality offering has long been discussed in the literature. Maksimovic and Titman (1991) provide a model of firms' behavior under ec onomic stress by considering a finite horizon model where they study the quality choices of all-equity and leveraged firms. Their model assumes an ex-ante inability of consumers to understand the quality of the product. This framework allows firms with a degree of freedom on the selection of the provided quality, how ever, a penalty from the customers exists, if it is revealed that the firm offers products of low er quality. Nevertheless, under specific conditions, and, in order to gain a short-term profit, firms may choose to produce a low-cost product and price it as a highcost. This strategy is more likely to appear in financially distressed firms trying to avoid bankruptcy or in firms under the expectation of adverse financial conditions in the near future. Firms grouped under these categories have an inc entive to trade-off the level of the offered product quality to maximize their current profit. This strategy is described as a form of an "involuntary loan" sourced from customers while a possible loss of reputation could be considered as a form of loan repayment.

The same effect may take place in business-to-business settings. In regards to service structure, typical risk and coordination issues in a service supply chain may also explicate the willingness of the supplier to offer substandard service (in some cases bundled with optimal servic es) to enhance its profit 
margin (Li, Chen, \& Chen, 2016). From the passenger viewpoint, this can have a long-term impact on the reputational effect of the airline as regards passenger loyalty (Caruana, 2002), thus, leading frequent passengers to switch after a consistent series of service failures (Chen \& Chang, 2008). Nonetheless, the switching effect requires the presence of effective alternatives for consumers, but many routes are operated by a single airline (or a few more, subject to demand and slot availability). As such market concentration and competition may impact profitability at a higher level when service quality is suboptimal. Steven et al. (2016) suggest that that market concentration dampens the relationship between customer satisfaction and airline profitability suggesting that providing optimal quality to passengers has marginal effects on their satisfaction when dominance is high on particular routes.

Several empirical studies confirm these theoretical expectations. Phillips and Sertsios (2013) examine the airline quality and pricing decisions under financial distress or bankruptcy and report that firms with financial distress take advantage of other stakeholders. Matsa (2011) provides additional empirical evidence through observing supermarkets' behavior uncovering that highly leveraged firms degrade their product quality to ease their debt schedule. While existing studies focus on firm-specific information, we explore broader economic conditions and their effect on the performance of the whole sector. We outline these factors in the subsequent section.

\subsection{Critical Cost Components of Airline Service Performance}

While it is recognized that aviation is a mature, capital-intensive industry with high operating costs and low profit margins (Behn \& Riley, 1999), methods of financing such as aircraft leases, and computerization of processes have minimized upfront costs required for an airline to operate efficiently. Nonetheless, cost components such as fuel and capital access costs (captured through interest rates) are identified as systematic drivers of an airline's financial performance (Vasigh, Fleming, \& Humphreys, 2014). According to IATA ${ }^{1}$, fuel cost accounts for 20 to 30 percent of total operating expenses. Moreover, increases in the fuel costs are associated with deterioration of the financial performance of

\footnotetext{
${ }^{1}$ IAT A Industry Fact Sheet. Available at: https://www.iata.org/pressroom/facts_figures/fact_sheets/Documents/factsheet-fuel.pdf
} 
an airline. Fuel price is also a critical determinant of air passenger and freight demand (Hakim \& Merkert, 2017).

In order to keep the operating margins stable, airlines may respond by allocating less capital in other cost components, such as labor costs or ground handling expenses as well as investment decisions in new aircraft and fleet modernization. This is not something unexpected given that the effect of airline service quality and the subsequent passenger satisfaction on firm profitability is not always clear. For example Merkert and Pearson (2015) report a lack of significant relationship of passenger satisfaction and service quality on airline profitability, signifying that investments in such aspects may not reap financial benefits. As such, management may have a degree of freedom on selecting the service quality levels of the airlines, though, an after-effect of cost reduction policies is the degradation of quality standards offered to passengers. How fuel costs impact airlines' decisions can be found in several cases in the recent past. For example, air carriers have been accused that select optimal, from a fuel consumption perspective, flying routes although these can be lengthier or sometimes riskier. ${ }^{2}$ Another strategy which also falls into that direction is the lengthening of route durations in order to account for unexpected delays, a practice that is also known as schedule padding. ${ }^{3}$

Furthermore, airlines are firms operating on high leverage and as such the volatility of fuel costs makes them more susceptible to cash flow swings (Morrell \& Swan, 2006). Gilchrist and Himmelberg (1995) argue about the excessive sensitivity of investments to cash flow fluctuations. Airlines adapt fuel hedging strategies or fuel surcharges to mitigate fuel cost and volatility. However, not all c arriers follow the same hedging strategy as many are aggressively hedged while others very limitedly or any at all. Extant literature also reports that more constrained airlines hedge less (Rampini, Sufi, \& Viswanathan, 2014). Moreover, periods of sharp drops in oil prices could have the opposite result and lead to significant losses. ${ }^{4}$ The optimality of hedging decisions is debated in the literature, and there is no

\footnotetext{
${ }^{2}$ An example is the case of Malaysian Airways Flight MH17 which was shot down over Ukraine with many analysts questioning the airline's decision to fly over an airspace where an ongoing conflict was taking place.

${ }^{3}$ Condé Nast Traveler (August, 2018): Airlines are padding flight times to avoid being 'Late'. Available online at: https://www.cntraveler.com/story/airlines-are-padding-flight-times-to-avoid-being-late

${ }^{4}$ Delta in Q4 of 2014 reported $\$ 712$ million loss mainly as a result of fuel hedge settlements.
} 
consensus whether airlines should hedge (Morrell and Swan, 2006) or not, since evidence may suggest that hedging can be an insignificant strategy in the long run (Lim \& Hong, 2014).

The second cost component that we consider is the capital borrowing cost expressed by interest rates. Airlines are capital intensive firms, heavily leveraged and, therefore, very sensitive to interest rate fluctuations (Guzhva \& Pagiavlas, 2003). As such, variations in the borrowing cost induce a significant cost for airlines. Although individual borrowing costs may vary for each airline, a common approach is to estimate it through the interbank lending rate. As a benchmark, the interbank rate has a direct effect on interest payments and credit ratings of the loan portfolios or other financial instruments such as bonds and leasing agreements. Several theoretical frameworks that evaluate investment decisions under financial constraints revealthat firms are less reluctant to provide lower quality standards. Myers (1977) introduced the underinvestment problem by arguing how the corporate debt can reduce the set of investing opportunities that derive from an increase in the required rate of return which rejects formerly profitable projects. To provide a clear picture of the debt pressures US airlines face in the postderegulation era, all major US airlines have filled at least once for bankruptcy protection under Chapter 11 and the number of total bankruptcies is close to 200 , according to a list provided by the Airlines for America (A4A) industry group. ${ }^{5}$

While the effect of these two factors is unexplored in an airline service quality setup, the level of market concentration has received attention from both researchers and regulators, but this takes place by considering the route-based competition quality (Greenfield, 2014; Mazzeo, 2003; Rupp, Owens, Plumly, \& others, 2006). We argue that the market-level competition will be more revealing of the cost pressures than the competition on the route basis because airlines are active in many routes. The results of this field of research are inconclusive. Swan (1970) claims that the quality of the goods produced should be identical to different levels of market concentration. On the contrary, Spence (1975) finds that "an unregulated monopolist's selection of product characteristics is likely to be biased away from the social optimum." During the deregulation period introduced with the Airline Deregulation Act of 1978 , this was also a core part of the debate between proponents and opponents as the former suggest

\footnotetext{
${ }^{5}$ The relevant list is found in http://airlines.org/data/u-s-bankruptcies-and-services-cessations /
} 
that the competition will increase the quality while the latter express concerns for inexperienced carriers or fierce competition.

\section{Data and Variables}

\subsection{Datas et and operationalization of variables}

Our dataset consists of 158 monthly observations covering the period from June 2003 to July 2016. Our response variables are four widely used performance measures reported by the US Department of Transportation (DOT) on a monthly basis: (a) the number of delayed flights' (Delayed), (b) the flight cancellations (Cancelled), (c) the mishandled baggage (Mishandled), and the customer complaints (Complaints). For the first two metrics, we compute our aggregated variable from the on-time performance data report from $06 / 2003$ that includes information for all flights and carriers. For the last two quality performance metrics, we gather information from the Air TravelConsumer Report (ATCR). In this report, both the minutes delayed per flight and the number of flight cancellations are presented by the cause of delay (or canc ellation).

Having that information at hand allows us to discriminate the delays (or cancellations) that stem from a carrier's operational aspects rather than exogenous factors such as weather or security reasons. As such, we attribute as flight cancellations only those with cancellation code " $A$ " that stands for "Carrier fault". For the delays, we use the number of flights with more than 15 minutes delay to the number of performed flights. The 15 minutes limit is the threshold used by the US DOT for a flight to be considered as delayed. These variables, among others, are also used for the construction of the national Airline Quality Rating (AQR) study of major airlines performance in the United States which is conducted jointly by Wichita State University and Embry-Riddle Aeronautical University in Prescott (Headley and Bow en, 1997) while they have also been considered as a proxy of service quality in several academic studies (Gursoy, Chen, \& Kim, 2005; Steven et al., 2016; Tiernan, Rhoades, \& Waguespack Jr, 2008). All explanatory and response variables are provided on a monthly basis allowing for a more valid statistical analysis compared to studies that employ mixed time-frequency data. 
Regarding the operationalization of the explanatory variables, we consider fuel cost $(F u e l)$, the interbank lending rate (Interbank) and the level of competition $(H H I)$ for the airline industry. We extract the fuel cost using monthly data of US Gulf Coast kerosene-type jet fuel spot price FOB (dollars per gallon) retrieved from the EIA US Energy Information Administration. Interbank rate values are taken from the Federal Reserve Bank of St. Louis (FRED). We employ the Herfindahl-Hirschman index to measure market concentration. We collect data from the T-100 domestic segment report to construct the Herfindahl-Hirschman Index (HHI) excluding cargo carriers. The HHI is computed as:

$$
H H I=\sum_{n=1}^{N} S_{i}^{2},
$$

where in a market with $N$ participants, $S_{i}$ is the market share of the $i$-th firm computed as the fraction of Revenue Passenger Miles (RPM) of this carrier over the total RPM's for a specific month recorded in the DOT database.

A graphical representation of the monthly $H H I$ during the study period is depicted in Figure 1 . In the first half of the period under consideration the market becomes less concentrated. How ever, since 2009 we notice considerable spikes, and the reverse pattern is observed because of the various mergers that took place during that period that coincides with the global financial crisis (e.g., American Airlines with T.W.A and latter with US Airways, Delta with Northwest).

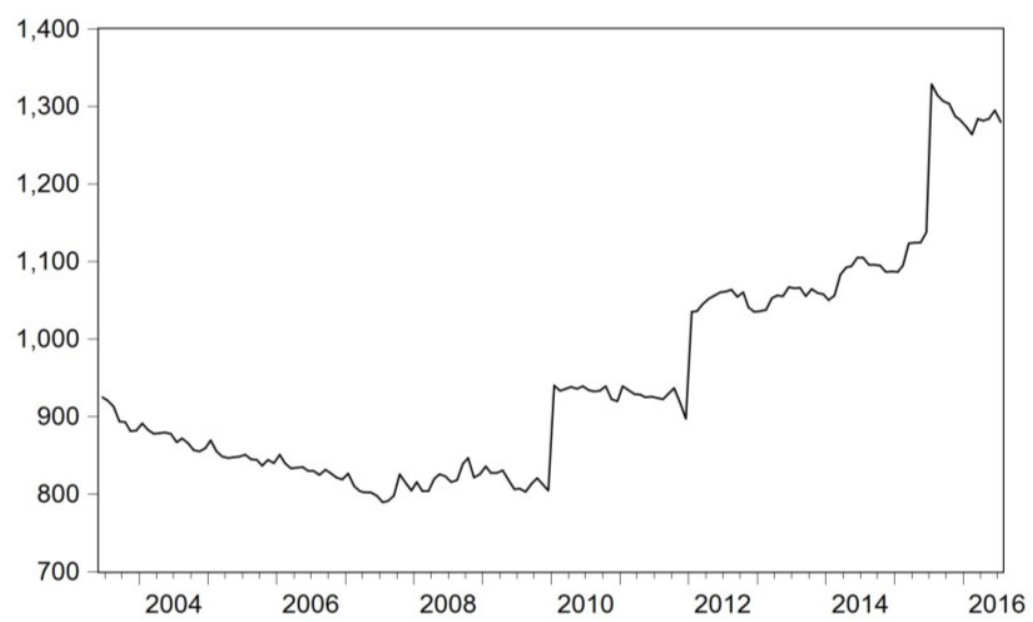

Figure 1: HHI index in the airline industry for period 2003-2016

In addition, we control for the number of flights of each carrier to allow for capacity load effects. To account for seasonality due to different airline schedules and operating conditions such as airport congestion, we also employ monthly dummies. 


\section{Empirical Analysis}

\subsection{Des criptives, Methodology and Empirical Results}

A descriptive analysis of the variables used in this study is provided in Table 1. The worst month concerning on-time performance solely attributed to the airline, was December 2007 with a total of 55,017 delayed flights (for more than 15 minutes), while flight cancellations peaked at 30,852 events in January 2014 , mishandled baggage events were maximized in December 2004 with 9.11 cases per 1,000 passengers and customer complaints were soared up to 2.8 per 100,000 passengers in July 2012.

Figure 2 provides a graphical depiction of the time series under consideration.
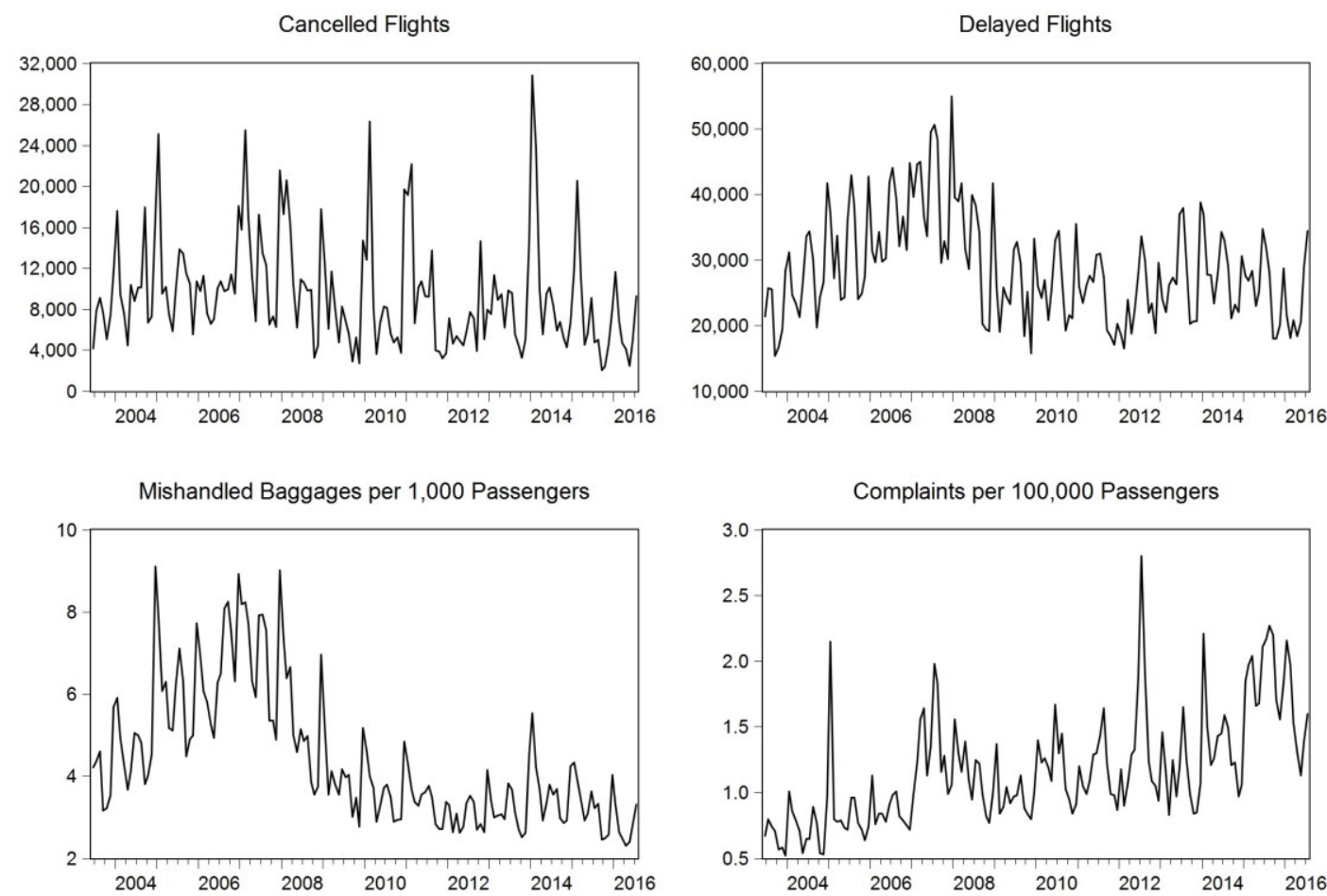

Figure 2: Graphical representation of service measures for the period 2003-2016

We also assess the stationarity of our dependent and independent variables based on the results of three tests; the Augmented Dickey-Fuller test (ADF), the Phillips-Perron test (PP) and the KwiatkowskiPhillips-Schmidt-Shin test (KPSS) including an intercept and a linear trend in the test specification.

Table 1: Descriptive Statistics 


\begin{tabular}{l|llll|lll|l}
\hline & Delayed & Cancelled & Mishandled & Complaints & Fuel & Interbank & HHI & \#Flights \\
\hline Mean & 28,680 & 9,424 & 4.41 & 1.17 & 2.13 & 1.62 & 951.82 & 535,281 \\
Median & 27,536 & 8,255 & 3.82 & 1.07 & 2.06 & 0.54 & 918.99 & 533,014 \\
Max & 55,017 & 30,852 & 9.11 & 2.80 & 3.89 & 5.49 & $1,329.20$ & 640,984 \\
Min. & 15,375 & 2,075 & 2.31 & 0.52 & 0.74 & 0.11 & 789.40 & 406,883 \\
S.D. & 7,965 & 5,309 & 1.64 & 0.42 & 0.77 & 1.87 & 143.59 & 52,067 \\
\hline
\end{tabular}

Note: Delayed refers to the number of flights that are delayed for more than 15 minutes due to carrier's responsibility, Cancelled is the number of cancelled flights with carrier's responsibility, Mishandled is the number of mishandled baggage per 1,000 customers, and Complaints is the volume of complaints per 100,000 passengers. Fuel is the US Gulf Coast kerosenetype jet fuel spot price FOB (in dollars per gallon). Interbank refers to the Interbank rate retrieved from FRED Federal Reserve Bank of St.Louis. HHI is the Herfindahl-Hirschman Index which is computed from the T-100 domestic segment report from the Bureau of T ransportation Statistics and Flights is the number of flights performed estimated from the on-time performance report.

Results show that our variables are a battery of integrated of order zero, I(0), or one, I(1), time series. In that case, Pesaran and Shin (1999) and Pesaran et al. (2001) propose the ARDL Bounds approach to test for the relationship between the variables of interest at levels irrespectively of whether these are I(0), I(1) or mutually cointegrated. Pesaran and Shin (1999) show that short-run parameters are $\sqrt{T}$ consistent, and long parameters are super consistent and asymptotically normal irrespective of the order of integration. This approach compared to conventional cointegration tests such as the one developed by Engle and Granger (1987) and Johansen and Juselius (1990) have several advantages. In addition to permitting a mixture of integration order for the explanatory variables, the ARDL model is expressed as a single equation set-up with flexible selection of lag lengths while it is also suitable for small sample sizes.

The general $\operatorname{ARDL}(p, q, \ldots, q)$ model is generally defined, assuming the same $\mathrm{q}$ for the independent variables, as follows:

$$
y_{t}=a_{0}+a_{1} t+\sum_{n=1}^{p} \gamma_{n} y_{t-n}+\sum_{n=0}^{q} \beta_{k} x_{t-n}+\epsilon_{t}
$$

where $t=\max (p, q), \cdots, T . x_{t}$ is a vector of $k \times 1$ explanatory variables that are allowed to be $\mathrm{I}(0), \mathrm{I}(1)$, or cointegrated and $\epsilon_{t}$ represent the residuals. $\alpha_{0}$ is the constant term, $\alpha_{1}$ is the coefficient of the time trend and $\gamma_{n}$ and $\beta_{k}$ are the coefficients for the lags of the dependent variable and $\mathrm{k}$ regressors, 
respectively. The lag orders $p$ and $q$ are obtained using either the Akaike (AIC) or Bayesian (BIC) information criteria and may vary across the different independent variables employed in our econometric specification (delays, cancellations, the volume of mishandled baggage and customer complaints). The later allows for various specifications of $p$ and $q$ to be considered to optimize the model selection (e.g., different lag orders for each of the independent variables). As such, the model is subsequently reparameterized in a conditional error-correction representation described by:

$$
\Delta y_{t}=a_{0}+a_{1} t-\varphi\left(y_{t-1}-\theta x_{t}\right)+\sum_{n=1}^{p-1} \psi_{n} \Delta y_{t-1}+\sum_{n=0}^{q-1} \omega^{\prime} \Delta x_{t-n}+\epsilon_{t}
$$

where $\varphi=1-\sum_{k=1}^{p} \gamma_{n}$ denotes the speed of adjustment and $\theta=\frac{\sum_{k=0}^{q} \beta_{k}}{\varphi}$ the long-run coefficients. The model is estimated by means of ordinary least squares. The suggested bounds test is based on a standard Wald test for the joint hypothesis: $H_{0}: \varphi=0 \cap \sum_{k=0}^{q} \beta_{k}=0$.

We utilize the model specification in (3) to test the association of the four response variables that measure various quality aspects with economic variables controlling for the number of flights and seasonal dummies. The first step of our analysis involves the selection of the proper number of lags for our models. We base our lag selection on the AIC and BIC criteria providing the selection of the following models: an $\operatorname{ARDL}(4,3,3,1)$ for delayed flights, an $\operatorname{ARDL}(1,7,3,0)$ for flight cancellation, an $\operatorname{ARDL}(11,3,2,0)$ for the mishandled baggage and an $\operatorname{ARDL}(1,2,0,0)$ for passenger complaints. In each specification, the first number corresponds to the number of lags for the dependent variable and the subsequent numbers to the number of lags for fuel, interbank rate, and HHI, respectively.

Panel A in Table 2 provides the results of the estimation where we report the coefficients along with standard errors in parentheses for each regressor. Interbank rate is consistently found to have a statistically significant long run effect on the service performance aspects with the exemption of passenger complaints. Market concentration (HHI) is also found to have a significant negative relationship with mishandled baggage and a weaker (at 10\%) significant effect on flight cancellations. The effect of fuel cost is insignificant in all cases suggesting that airlines do not alter the operational standard as a response to sudden fuel price changes and accurately reflect increases in the fuel cost in 
the minimum fare that has been calculated for a given flight. Considering the magnitude of the coefficients, the effects are not negligible as in the case of interest rates every month a $0.25 \%$ increase is associated on average with 580 increase in flight delays, 241 more flight cancellations and 14 additional cases of mishandled baggage per 100,000 passengers.

We also report the F-test values of the bound test and the long run relationship among our variables of interest with the service quality measures that were specified before. In Panel B, we report the critical values for the models for various levels of significance. For all depended variables we cannot reject the null hypothesis of no long-run relationship at $5 \%$ or $1 \%$. Additionally, the adjustment speed, which is informative about the rate of convergence to equilibrium, is highly significant for all models and with the expected negative value between 0 and -1 according to model requirements. In particular, the adjustment speed ranges between -0.33 to -0.66 indicating that deviations from the long-term equilibrium are corrected by approximately 33 to 66 percent the following month.

Table 2: The long-run relationship between the interest rate (Interbank), fuel prices (Fuel) and market concentration (HHI)with the dimensions of airline service performance.

Panel A: ARDL Output

\begin{tabular}{lcccc}
\hline \multicolumn{5}{c}{ Dependent Variables: } \\
\hline \\
Delayed & Cancelled & Mishandled & Complaints \\
\hline Fuel & -121.58 & -283.11 & -0.20 & 0.07 \\
& $(1,260.74)$ & $(835.72)$ & $(0.11)$ & $(0.08)$ \\
Interbank & $2,317.48^{* *}$ & $962.54^{*}$ & $0.57^{* *}$ & 0.06 \\
& $(735.39)$ & $(464.16)$ & $(0.07)$ & $(0.05)$ \\
HHI & 7.16 & -10.90 & $-0.002^{*}$ & 0.00 \\
& $(9.59)$ & $(5.97)$ & $(0.00)$ & $(0.00)$ \\
\hline Speed ofAdjustment & $-0.33^{* *}$ & $-0.66^{* *}$ & $-0.64 *$ & $-0.33^{* *}$ \\
& $(0.09)$ & $(0.08)$ & $(0.12)$ & $(0.06)$ \\
\hline Obs & 154 & 151 & 147 & 156 \\
Adj. R & 0.85 & 0.50 & 0.91 & 0.72 \\
LM & 1.57 & 2.32 & 0.05 & 1.29 \\
F-test & 4.035 & 16.039 & 7.257 & 7.149 \\
\hline & Panel B: Critical Value Bounds ofF-test & $1 \%$ \\
\hline Sign. Level & $10 \%$ & $5 \%$ & $2.5 \%$ & 4.29 \\
\hline Lower Bound & 2.72 & 3.23 & 3.69 & 5.61 \\
\hline Upper Bound & 3.77 & 4.35 & 4.89 & \\
\hline
\end{tabular}

Note: Panel A reports the coefficients along with normal standard errors in parentheses for Fuel, Interbank rate and HHI. LM presents whether the residuals are serially correlated following the Breusch-Godfrey LM test. F-test values for the null hypothesis of no long-run relationships. Critical values are reported in Panel B for various significance levels based on Pesaran et al. (2001). *,* stars denote significance at the $5 \%$ and $1 \%$ level, respectively. 

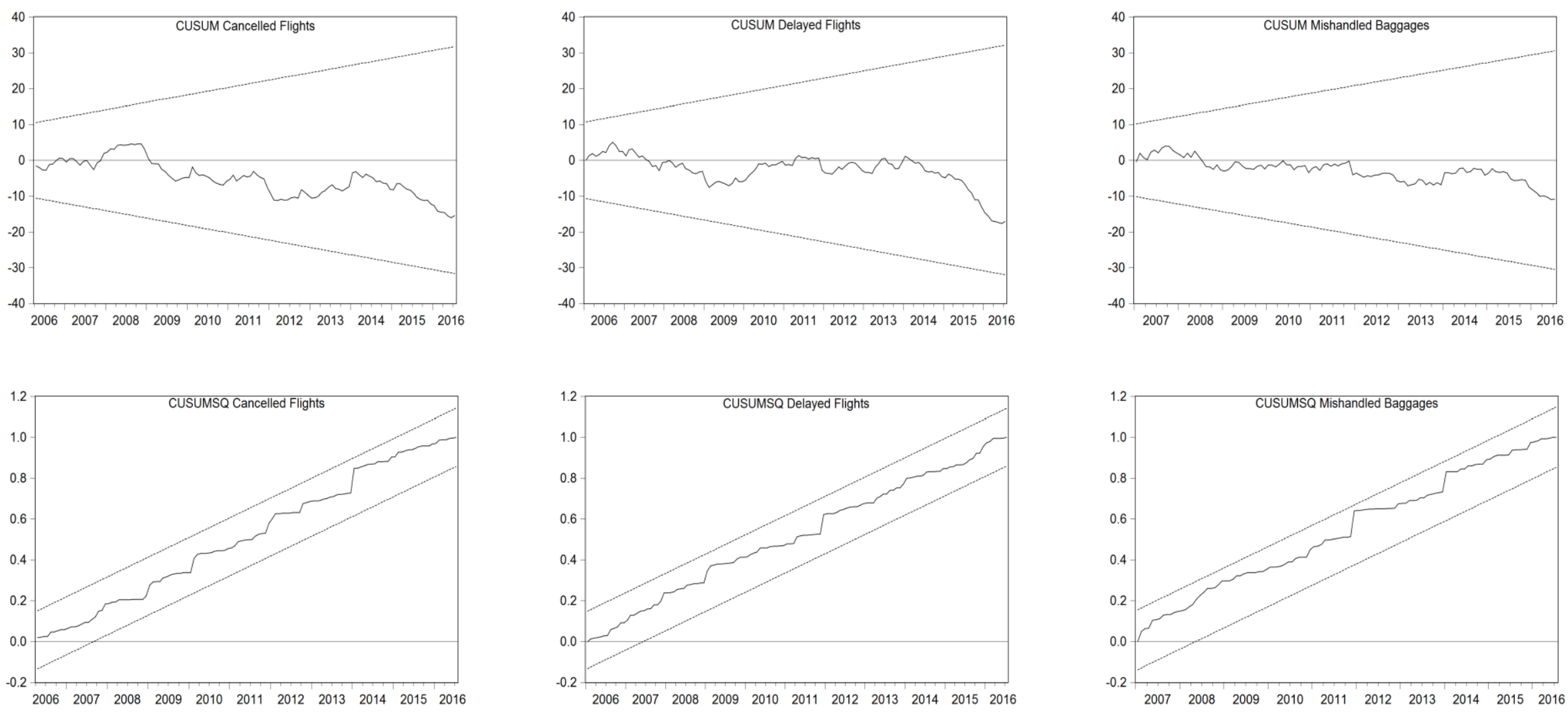

Figure 3: CUSUM and CUSUMQ model stability tests. Relevant residual lines are within the $5 \%$ significance boundaries. This implies that the estimated parameters are stable over the whole sample period. 
Considering the results of the model, we want to evaluate whether there are particular issues that may affect the results. More specifically, we examine whether two necessary conditions for consistent results in the ARDL bound approach are met. The first condition requires that the residuals should be serially uncorrelated. In so doing, we test the residuals using the Breusch-Godfrey LM test, and in all cases, the null hypothesis of serial correlation is rejected. The results are presented in Panel A of Table 2. The stability of our models is also evaluated using both the cumulative sum (CUSUM) and the cumulative sum of squares (CUSUMSQ) of the residuals for constancy over time. Results for the three categories that were found to have a long run relationship with our variables of interest are presented in Figure 3.

Table 3: The long-run relationship of interest rate, fuel prices and market concentration with airline service performance including structural breaks and trend.

\begin{tabular}{lcccccc}
\hline & \multicolumn{2}{c}{ Delayed } & \multicolumn{2}{c}{ Mishandled } & \multicolumn{2}{c}{ Complaints } \\
\hline ARDL Specification & $\begin{array}{c}\text { Str. Breaks } \\
(4331)\end{array}$ & $\begin{array}{c}\text { Str. Breaks + Trend } \\
(4371)\end{array}$ & $\begin{array}{c}\text { Str. Breaks } \\
(11320)\end{array}$ & $\begin{array}{c}\text { Str. Breaks + Trend } \\
(11320)\end{array}$ & $\begin{array}{c}\text { Trend } \\
(1006)\end{array}$ \\
\hline Fuel & -34.47 & -901.43 & -0.21 & -0.17 & -0.09 \\
& $(1,247.55)$ & $(1,360.83)$ & $(0.11)$ & $(0.13)$ & $(0.07)$ \\
Interbank & $2,353.17^{* *}$ & $1,820.95^{*}$ & $0.57^{* *}$ & $0.58^{* *}$ & 0.06 & $(0.04)$ \\
HHI & $(736.94)$ & $(464.16)$ & $(0.07)$ & $-0.07)$ & -0.00 & $(0.00)$ \\
& 6.93 & -9.82 & $-0.00^{*}$ & $(0.00)$ & $-0.61^{* *}$ & $-0.43^{* *}$ \\
Speed of Adjustment & $(9.49)$ & $(14.07)$ & $-0.64^{* *}$ & $0.13)$ & $(0.07)$ \\
\hline Obs & $-0.33^{* *}$ & $-0.36^{* *}$ & $(0.12)$ & 147 & 152 \\
AdjR & $(0.09)$ & $(0.08)$ & 0.91 & 0.91 & 0.73 \\
\hline
\end{tabular}

Note: Normal standard errors reported in parentheses. One, two stars denote significance at the $5 \%$ and $1 \%$ level, respectively.

The second condition requires that the stability of the models should be assured, assuming that the selection of the lagged parameters is independent of local properties of the sample (e.g., the great recession of 2008 and signific ant mergers taking place in the market thereafter). To this end, we have the opportunity to examine for signific ant effects of structural breaks and linear trends. With an eyeball test on the time series of the four quality aspects in our test period in Figure 2, we see that all but the volume of cancelled flights display such behavior. Specifically, the delayed flights and mishandled baggage experience a structural break around 2008, while passenger complaints follow an upward trend. We perform a Bai-Perron breakpoint test which reveals two possible structural breaks for delayed 
flights (August 2008 and May of 2006). For mishandled baggage, the test points out to a structural break in September 2009.

Accordingly, we model complaints including a trend variable while for delays and mishandled baggage we employ two alternative specifications. The first specification includes dummy variables for the months denoted as structural breaks and the second specification is augmented with a trend variable. Results reported in Table 3 reveal that our results are robust even taking into account possible structural breaks and (or trends).

\section{Discussion}

\subsection{Theoretical Implications}

How firms adjust the quality of their service offering when they are under financial stress is an issue that has been the focus of several streams in the literature. Theoretical models discuss the underinvestment problem or the trade-off between quality and profit in periods of financial stresses or liquidity constraints (Golbe, 1988; Maksimovic \& Titman, 1991). We investigate this hypothesis by examining the effect of fuel cost, interest cost and level of market competition in airline quality focusing on systematic factors that may affect the whole sector than firm-level and found evidence to support the theory.

In three out of the four quality metrics that were evaluated, we find statistically significant results supporting that interest rates (and subsequent borrowing costs) may affect the number of delays, number of cancellation and mishandled baggage. Similar but weaker results are found for the effect of market competition, where at periods of higher concentration service performance is superior. The association of fuel cost with service quality is not confirmed, most possibly due to the fuel surcharge component that airlines have introduced in their ticketing. From a managerial view point, our results point out the importance of the stability in interest rates for airlines to guarantee the service quality levels. Airlines are highly leveraged firms, operating with tight profit margins with long decision horizons and as such the relative cost that may be incurred by opting for a fixed interest rate versus a variable one during the configuration of a financial instrument can have a consequence to their operational performance. 
How ever, the effect of such variables in the variations of service level performance may not be directly attributed to firm choices. As we argue in the introductory part of this study, the vast web of different firms involved in the delivery of aviation services can constitute a firm-level analysis myopic and disregard the influence of trusted partners across the whole spectrum of the value chain of the aviation industry (Tretheway \& Markhvida, 2014).

\subsection{Practical Implications}

The deregulation of the aviation industry, first in the US and second in the EU (through the open skies agreement) has substantially altered the face of civil aviation in the past 30 years. While airlines have grasped the opportunity to gain market share over other competitive forms of travel, the commoditization of service offerings across the industry and the upwards trend towards a higher number of passengers traveling from particular destinations has created a set of new challenges, especially in the airline competition landscape. While passengers often do not have the choice of choosing which airline to travel with, for particular types of travelers (e.g., business class) service level performance is a particular factor that influences their choices. Airline performance in these settings may be characterized as either pro-active or re-active depending on the particular control that the airline can exercise upon its outcome. While several airlines have tried to develop customer-friendly approaches utilizing frontline employees (e.g., Carlzon, 1987) in service recovery scenarios, these approaches have often mixed results. Even though these cases can be handled by the airline itself in a timely manner, outsourced services introduce co-ordination costs between the airline, the customer and the service provider, with the airline been credited for the bad performance of its service partner in case the customer is dissatisfied.

The results highlighting the lagged dependence of access to capital with the volume of mishandled baggage may be partially explained by the overstretching of human resources as a result of cost-cutting measures on ground handling. The institution and enforc ement of service level agreements in that aspect is an important parameter to consider, and airline operation managers should monitor the financial health of their partners in order to ensure the minimum service delivery level. While IATA 
has introduced guidelines on how service level agreements should be facilitated ${ }^{6}$ between airlines, ground handlers and airport authorities, the enforcement and monitoring of these agreements is a challenging task for every partner involved.

A second implication to consider is the case of benchmarking service level performance which is often done in a comparison between airlines. As such, the influence of general market variations in service level performance that can be partially explained by macroeconomic indicators can provide a more accurate depiction on why these performance metrics change over time. This can be of value not only to consumer groups advocating for better services but also for operation managers who need to look at service level performance in relation with a global benchmark rather than the competition itself.

\section{Conclusions, limitations and future research}

The question whether macroeconomic indicators can describe variations of service level performance across the aviation industry is of particular importance since economic cycle variation has been shown to directly influence the expansion (or contraction) of passenger numbers for particular carriers and destinations (Dekimpe, Peers, \& van Heerde, 2016). In this study, we employ a massive open dataset from the US Department of transport and airline consumer reports to study whether particular indic ators of economic activity such as fuel prices and capital borrowing costs have an effect on various aspects of airline service quality.

While this study is novel and contributes to the understanding of drivers affecting servic e level performance in industries characterized by high complexity in their service supply chains, it does not come without limitations. Considering the nature of the research setting and the data used, our results are only specific to US operating carriers and as such exclude the influence of international airlines. Second, our study considers the market as a whole without exploring if the effect is similar on the service performance of different categories of service providers as for example between low -cost and legacy carriers. Third, particular characteristic s such as culture and perceptions about customer service

\footnotetext{
${ }^{6}$ Airport Service Level Agreement guidance https://www.iata.org/policy/infrastructure/Documents/airportservice-level-agreement.pdf
} 
tend to exacerbate or reduce the intensity of service complaints (see for example, Stamolampros, Korfiatis, Kourouthanassis, \& Symitsi, 2019). As such the results are not generalizable on other markets and can only describe particular characteristics of the US aviation industry.

In addition to extending the finding in an international context or between different categories of airline providers, future research could consider the effect of different cost components and infrastructural elements in the service level performance of particular airlines. For instance, the influence of human resources (especially in the cases of service failure resulting to complaints) as well as issues with airport congestion and air traffic control restrictions are underexplored. 


\section{References}

Babbar, S., \& Koufteros, X. (2008). The human element in airline service quality: contact personnel and the customer. International Journal of Operations \& Production Management, 28(9), 804 830.

Behn, B. K. \& Riley, R. A. (1999). Using Nonfinancial Information to Predict Financial Performance: The Case of the U.S. Airline Industry. Journal of Accounting, Auditing \& Finance, 14(1), 29 56.

Carlzon, J. (1987). Moments of truth. Ballinger Cambridge, MA.

Caruana, A. (2002). Service loyalty: The effects of service quality and the mediating role of customer satisfaction. European Journal of Marketing, 36(7/8), 811-828.

Chen, C.-F., \& Chang, Y.-Y. (2008). Airline brand equity, brand preference, and purchase intentionsThe moderating effects of switching costs. Journal of Air Transport Management, 14(1), 40 42.

Choi, T.-M., Wallace, S. W., \& Wang, Y. (2016). Risk management and coordination in service supply chains: information, logistics and outsourcing. Journal of the Operational Research Society, $67(2), 159-164$.

Chou, C.-C., Liu, L.-J., Huang, S.-F., Yih, J.-M., \& Han, T.-C. (2011). An evaluation of airline service quality using the fuzzy weighted SERVQUAL method. Applied Soft Computing, 11(2), 2117 2128.

David Mc A, B. (2013). Service quality and customer satisfaction in the airline industry: A comparison between legacy airlines and low-cost airlines. American Journal of Tourism Research, 2(1), $67-77$.

Dekimpe, M. G., Peers, Y., \& van Heerde, H. J. (2016). The impact of the business cycle on service providers: Insights from international tourism. Journal of Service Research, 19(1), 22-38.

Dionne, G., Gagné, R., Gagnon, F., \& Vanasse, C. (1997). Debt, moral hazard and airline safety An empirical evidence. Journal of Econometrics, 79(2), 379-402. 
Engle, R. F., \& Granger, C. W. (1987). Co-Integration and Error Correction: Representation, Estimation, and Testing. Econometrica, 55(2), 251-276.

Gilbert, D., \& Wong, R. K. (2003). Passenger expectations and airline servic es: a Hong Kong based study. Tourism Management, 24(5), 519-532.

Gilchrist, S., \& Himmelberg, C. P. (1995). Evidence on the role of cash flow for investment. Journal of Monetary Economics, 36(3), 541-572.

Golbe, D. L. (1988). Risk-taking by firms near bankruptcy. Economics Letters, 28(1), 75-79.

Greenfield, D. (2014). Competition and service quality: New evidence from the airline industry. Economics of Transportation, 3(1), 80-89.

Gursoy, D., Chen, M.-H., \& Kim, H. J. (2005). The US airlines relative positioning based on attributes of service quality. Tourism Management, 26(1), 57-67.

Guzhva, V. S., \& Pagiavlas, N. (2003). Corporate capital structure in turbulent times: a case study of the US airline industry. Journal of Air Transport Management, 9(6), 371-379.

Hakim, M. M., \& Merkert, R. (2016). The causal relationship between air transport and economic growth: Empirical evidence from South Asia. Journal of Transport Geography, 56, 120-127.

Hakim, M. M., \& Merkert, R. (2017). Econometric evidence on the determinants of air transport in South Asian countries. Transport Policy (Forthcoming).

Higgins, K, Lawphongpanich, S., Mahoney, J., \& Yin, Y. (2008). Evaluating airline service quality by data envelopment analysis. Transportation Research Record: Journal of the Transportation Research Board, (2052), 1-8.

Hussain, R., Al Nasser, A., \& Hussain, Y. K. (2015). Service quality and customer satisfaction of a UAE-based airline: An empirical investigation. Journal of Air Transport Management, 42, $167-175$.

Johansen, S., \& Juselius, K. (1990). Maximum likelihood estimation and inference on cointegration with applications to the demand for money. Oxford Bulletin of Economics and Statistics, 52(2), $169-210$. 
Korfiatis, N., Stamolampros, P., Kourouthanassis, P., \& Sagiadinos, V. (2019). Measuring service quality from unstructured data: A topic modeling application on airline passengers' online reviews. Expert Systems with Applications, 116, 472-486.

Li, S., Chen, J., \& Chen, B. (2016). Offering a downgraded service to enhance profit? Journal of the Operational Research Society, 67(2), 302-311.

Lim, S. H., \& Hong, Y. (2014). Fuel hedging and airline operating costs. Journal of Air Transport Management, 36, 33-40.

Liou, J. J., \& Tzeng, G.-H. (2007). A non-additive model for evaluating airline service quality. Journal of Air Transport Management, 13(3), 131-138.

Maksimovic, V., \& Titman, S. (1991). Financial policy and reputation for product quality. Review of Financial Studies, 4(1), 175-200.

Marazzo, M., Scherre, R., \& Fernandes, E. (2010). Air transport demand and economic growth in Brazil: A time series analysis. Transportation Research Part E: Logistics and Transportation Review, 46(2), 261-269.

Matsa, D. A. (2011). Running on empty? Financial leverage and product quality in the supermarket industry. American Economic Journal: Microeconomics, 3(1), 137-173.

Mazzeo, M. J. (2003). Competition and service quality in the US airline industry. Review of Industrial Organization, 22(4), 275-296.

Merkert, R., \& Pearson, J. (2015). A non-parametric efficiency measure incorporating perceived airline service levels and profitability. Journal of Transport Economics and Policy (JTEP), 49(2), $261-275$.

Morrell, P., \& Swan, W. (2006). Airline jet fuel hedging: Theory and practice. Transport Reviews, 26(6), 713-730.

Myers, S. C. (1977). Determinants of corporate borrowing. Journal of Financial Economics, 5(2), $147-$ 175.

Noronha, G., \& Singal, V. (2004). Financial health and airline safety. Managerial and Decision Economics, 25(1), 1-16. 
Pakdil, F., \& Aydm, Ö. (2007). Expectations and perceptions in airline services: An analysis using weighted SERVQUAL scores. Journal of Air Transport Management, 13(4), 229-237.

Park, J.-W., Robertson, R., \& Wu, C.-L. (2006). Modelling the impact of airline service quality and marketing variables on passengers' future behavioural intentions. Transportation Planning and Technology, 29(5), 359-381.

Pesaran, M. H., \& Shin, Y. (1999). An Autoregressive Distributed-Lag Modelling Approach to Cointegration Analysis. In S. Strøm (Ed.), Econometrics and Economic Theory in the 20th Century: the Ragnar Frisch Centennial Symposium (pp. 371-413). Cambridge: Cambridge University Press.

Pesaran, M. H., Shin, Y., \& Smith, R. J. (2001). Bounds testing approaches to the analysis of level relationships. Journal of Applied Econometrics, 16(3), 289-326.

Phillips, G., \& Sertsios, G. (2013). How do firm financial conditions affect product quality and pricing? Management Science, 59(8), 1764-1782.

Raghavan, S., \& Rhoades, D. L. (2005). Revisiting the relationship between profitability and air carrier safety in the US airline industry. Journal of Air Transport Management, 11(4), 283-290.

Rampini, A. A., Sufi, A., \& Viswanathan, S. (2014). Dynamic risk management. Journal of Financial Economics, 111(2), 271-296.

Rose, N. L. (1990). Profitability and Product Quality: Economic Determinants of Airline Safety Performance. Journal of Political Economy, 98(5), 944-964.

Rupp, N., Owens, D., Plumly, L., \& others. (2006). Does Competition Influence Airline On-Time Performance. Advances in Airline Economics, 1, 251-272.

Saha, G. C., \& Theingi. (2009). Service quality, satisfaction, and behavioural intentions: A study of low-cost airline carriers in Thailand. Managing Service Quality: An International Journal, 19(3), 350-372.

Saidi, S., Shahbaz, M., \& Akhtar, P. (2018). The long-run relationships between transport energy consumption, transport infrastructure, and economic growth in MENA countries. Transportation Research Part A: Policy and Practice, 111, 78-95. 
Spence, A. M. (1975). Monopoly, Quality, and Regulation. The Bell Journal of Economics, 6(2), 417429.

Stamolampros, P., Korfiatis, N., Kourouthanassis, P., \& Symitsi, E. (2018). Flying to Quality: Cultural Influences on Online Reviews. Journal of Travel Research (Forthcoming).

Steven, A. B., Yazdi, A. A., \& Dresner, M. (2016). Mergers and service quality in the airline industry: A silver lining for air travelers? Transportation Research Part E: Logistics and Transportation Review, 89, 1-13.

Swan, P. L. (1970). Durability of consumption goods. The American Economic Review, 60(5), 884894.

Tiernan, S., Rhoades, D. L., \& Waguespack Jr, B. (2008). Airline service quality: Exploratory analysis of consumer perceptions and operational performance in the USA and EU. Managing Service Quality: An International Journal, 18(3), 212-224.

Tretheway, M. W., \& Markhvida, K. (2014). The aviation value chain: Economic returns and policy issues. Journal of Air Transport Management, 41, 3-16.

Vasigh, B., Fleming, K., \& Humphreys, B. (2014). Foundations of Airline Finance: Methodology and Practice. New York: Routledge.

Wittman, M. D. (2014). Are low-cost carrier passengers less likely to complain about service quality? Journal of Air Transport Management, 35, 64-71. 